\title{
Synthesis and Characterization of Boron Modified Poly(ester amide) Derived from Jatropha Curcas Seed Oil
}

\author{
GHAZALA IMRAN*, SAGEER AHAMAD, I. ALTAF and S. A. AHMAD \\ Natural Product and Polymer Research Laboratory, Department of Chemistry, G.F. College \\ (M.J.P. Rohilkhand University), Shahjahanpur, U.P. 242001, India \\ hasnatgfc@rediffmail.com
}

Received 22 July 2015 / Accepted 1 August 2015

\begin{abstract}
Syntheses of practicable polymeric materials from the spectrum of natural renewable resource not only reduce the dependency on petrochemical but also help in environmental balance. Utilization of non-traditional and non-edible vegetable oils in polymer syntheses solves the waste disposal as well as maintains the equilibrium of demand and availability of raw materials. Jatropha curcas seed oil (JCSO) a renewable resource abundantly available utilized in synthesis of boron modified polyesteramide resin (JCBPEA). $N, N$-bis(2-hydroxy ethyl) Jatropha curcas fatty amide (HEJCA) was synthesize by aminolysis of JCSO with diethanolamine. HEJCA a diol condensed with phthalic acid to yield Jatropha curcas polyesteramide (JCPEA). To improve the performances and utility of JCPEA boron was incorporated in the polymer backbone to obtained Boron modified polyesteramide (JCBPEA). JCBPEA characterized by the measurement of physicochemical properties like specific gravity, refractive index, acid value, iodine value, soponification value. The structural elucidation of resin was carried out by spectral analyses.
\end{abstract}

Keywords: Jatropha curcas, Seed oil, Polyesteramide, Boron polymers

\section{Introduction}

Polymers from renewable resources have attracted increasing attention for the last few decades predominantly due to environmental concerns and realization that our petroleum resources are finite ${ }^{1-4}$. Over the past few years vegetable oils have served as a potential alternative of petroleum resources ${ }^{5-7}$. The utilization of seed oils in the manufacture of useful polymer based end products solved not only the problem of waste disposal but also it can help in bringing down the cost of production ${ }^{6,8}$.

Vegetable oil- a triglyceride of saturated and unsaturated fatty acids obtained from different plant seeds like linseed, Pogamia glabra, castor, soybean, sunflower etc. These oils have been largely used as a starting material in making numerous valuable polymers like polyurethanes, poly(ether-amide)s, alkyds, polyesteramides and many others ${ }^{7-10}$. These polymers have got prominent applications in the paints, coatings, biomedical and food industries ${ }^{11}$. Polyesteramide resins are amide modified alkyds which contain amide linkages 
in addition to ester and known for improve performances over traditional alkyds ${ }^{12-14}$. Incorporation of boron in the polymeric resins, known to improve the performances remarkably in terms of adhesion, resistance to scratch and flame retardant ability ${ }^{15,16}$.

Jatropha curcas is a medium sized tree largely cultivated in rural areas. It grows rapidly in hardy to dry weather. Jatropha curcas tree yielded non edible seeds which contain about $48 \%$ triglyceride oil of saturated and unsaturated fatty $\operatorname{acid}^{17}$. Literature survey reveals that JCSO is abundantly available in the country and not being utilized satisfactorily in the synthesis of specialty polymeric resins. Keeping these facts in mind in present work we have made an effort to utilize this seed oil in the synthesis of boron incorporated polyesteramide (JCBPEA) to provide more practicable utility to JCSO abundantly available renewable resource. The developed polymer was characterized by measuring physicochemical properties and spectroscopic analyses.

\section{Experimental}

The seeds of Jatropha curcas were collected from the G.F. College campus, Shahjahanpur, U.P., India. The oil was extracted from the dried and crushed seeds through the soxhlet apparatus using petroleum ether as a solvent $\left(60-80{ }^{\circ} \mathrm{C}\right)$. The physicochemical characterizations of JCSO are summarized in the Table 1. Phthallic acid, diethyl ether, methanol, boric acid were used of analytical grade (Merck-India). Diethanol amine of analytical grade procured from the s.d. Fine chemicals, India and was distilled under reduced pressure before use.

Table 1. Characterization of JCSO, HEJCA, JCPEA and JCBPEA

\begin{tabular}{cccccc}
\hline S.No. & Characterization & JCSO & HEJCA & JCPEA & JCBPEA \\
\hline 1. & Oil Content & 48 & - & - & - \\
2. & Gardener color no. & 4 & 5 & 6 & 5 \\
3. & Specific gravity & 0.927 & 0.938 & 0.948 & 0.988 \\
4. & Refractive index & 1.475 & 1.448 & 1.528 & 1.562 \\
5. & Iodine value & 75.18 & 30 & 24 & 12 \\
6. & Acid value & 4.45 & - & 10.6 & - \\
7. & Saponification value & 180 & - & - & - \\
\hline
\end{tabular}

\section{Syntheses}

N,N-bis (2-hydroxy ethyl) Jatropha curcas oil fatty amide (HEJCA) and Jatropha curcas Polyesteramide (JCPEA)

HEJCA and JCPEA were synthesized and characterize as per previously reported method ${ }^{18}$.

\section{Synthesis of boron modified polyesteramide (JCBPEA)}

JCPEA $(0.01 \mathrm{~mol})$ dissolved in xylene was placed in four necked round bottom flask fitted with Dean-stark trap, thermometer and mechanical stirrer. The content was heated at $80 \pm 5$ ${ }^{\circ} \mathrm{C}$ under continuous string, followed by slow addition boric acid $(0.004 \mathrm{~mol})$. After complete addition of boric acid the temperature was raised up to $140 \pm 10{ }^{\circ} \mathrm{C}$ and allowed to continue till the completion of reaction. The progress of reaction was monitored by the taking acid values at regular intervals ${ }^{3}$. After completion of reaction, the product was taken out from the reaction flask and excess of xylene was removed under reduce pressure to obtain JCBPEA. 


\section{Characterization}

Physicochemical characterizations like specific gravity, refractive index, acid value and iodine value were performed as per standard laboratory methods ${ }^{3,19}$. The structural elucidation of polymer sample was carried out by spectral analyses. The FT-IR spectrum of JCBPEA was taken on Perkin Elmer 1750 FT-IR spectrometer (Perkin Elmer Citus instruments Norwalk CT) using a $\mathrm{NaCl}$ cell. ${ }^{1} \mathrm{H}$ NMR and ${ }^{13} \mathrm{C}$ NMR spectra of the resin was recorded on Jeol GSX $300 \mathrm{MHz}$ FX-1000 spectrometer using deuterated chloroform as a solvent and tetra methyl silane as an internal standard.

\section{Preparation of coatings}

Coatings of JCPEA and JCBPEA resins were prepared on mild steel strips, $70 \times 25 \times 1 \mathrm{~mm}$ size for pysico-mechanical test and 30x10x1 mm size for corrosion/chemical resistance performances. The mild steel strips were polished on various grade of silicon carbide papers, then washed with distilled water, degreased with alcohol and carbon tetrachloride. They were dried under vacuum for several hours. The coatings were developed on these specimens by brush technique using solution of 60 -wt $\%$ of resins. Coated strips were baked at $210{ }^{\circ} \mathrm{C}$ for 20 minutes and $170{ }^{\circ} \mathrm{C}$ for 15 minutes of JCPEA and JCBPEA respectively. Elcometer (Model 345; Elcometer instrument, Manchester, UK) was used to measure the coating thickness. The thicknesses of these coatings were found between $75 \pm 5 \mu \mathrm{m}$. The coated samples were evaluated for the scratch hardness (BS 3900), bending test on conical mandrel, and impact resistance (IS: 101 part 5/Sec.31988) tests. Chemical/corrosion resistance tests of the coatings were performed in water, acid $(5-\mathrm{wt} \% \mathrm{HCl})$ and alkali $(5-$ $\mathrm{wt} \% \mathrm{NaOH})$, by pouring their solution in 3"- diameter porcelain dishes and dipping the coated specimens in aforementioned media. Periodic examinations were carried out until coating showed visual evidence of softening, deterioration in gloss, discoloration or weight loss (Table 2). The salt spray test (ASTM b117-94) was also performed in a salt mist chamber containing $3.5 \mathrm{wt} \% \mathrm{NaCl}$ solutions.

Table 2. Physico-mechanical and chemical corrosion/resistance properties of JCPEA and JCBPEA

\begin{tabular}{|c|c|c|}
\hline Resin code & JCPEA & JCBPEA \\
\hline \multicolumn{3}{|c|}{ Physico-mechanical properties } \\
\hline Bending test $(1 / 8$ in $)$ & Passes & Passes \\
\hline Gloss at $45^{\circ}$ & 45 & 80 \\
\hline Impact resistance (lb/in) & 100 & 200 \\
\hline Scratch hardness $(\mathrm{Kg})$ & 1.5 & 3.5 \\
\hline \multicolumn{3}{|c|}{ Chemical/corrosion resistance* } \\
\hline $\mathrm{H}_{2} \mathrm{O}$ (10 days) & $\mathrm{E}$ & $\mathrm{E}$ \\
\hline $\mathrm{HCl}(5-\mathrm{wt} \%) 10$ days & $\mathrm{D}$ & $\mathrm{E}$ \\
\hline $\mathrm{NaOH}(5-\mathrm{wt} \%) 2 \mathrm{hrs}$ & A & $\mathrm{C}$ \\
\hline $\mathrm{NaCl}(5-\mathrm{wt} \%) 10$ days & $\mathrm{D}$ & $\mathrm{E}$ \\
\hline
\end{tabular}

${ }^{*} A=$ Film detached; $B=$ Film partially detached; $C=$ Loss in gloss; $D=$ Slight loss in gloss; $E=$ Unaffected

\section{Results and Discussion}

Figure 1 show the scheme for the preparation of HEJCA, JCPEA and JCBPEA. Triglyceride oil reacts with diethanol amine in presence sodium methoxide to give HEJCA. The HEJCA undergo polycondensation reaction with phthalic acid to produce JCPEA. JCPEA contain both hydroxyl and carboxylic groups at terminals. The carboxyl terminal of JCPEA coupled 
with the $\mathrm{B}(\mathrm{OH})_{3}$ and produces boron modified polyesteramide (JCBPEA). The analytical analyses indicate that decrease in hydroxyl value and acid value both by conversion of HEJCA to JCPEA. This is due to formation of ester linkage by the condensation of these groups. The further decrease in acid values during the formation of JCBPEA indicates the reaction of carboxylic acid of JCPEA with boric acid.
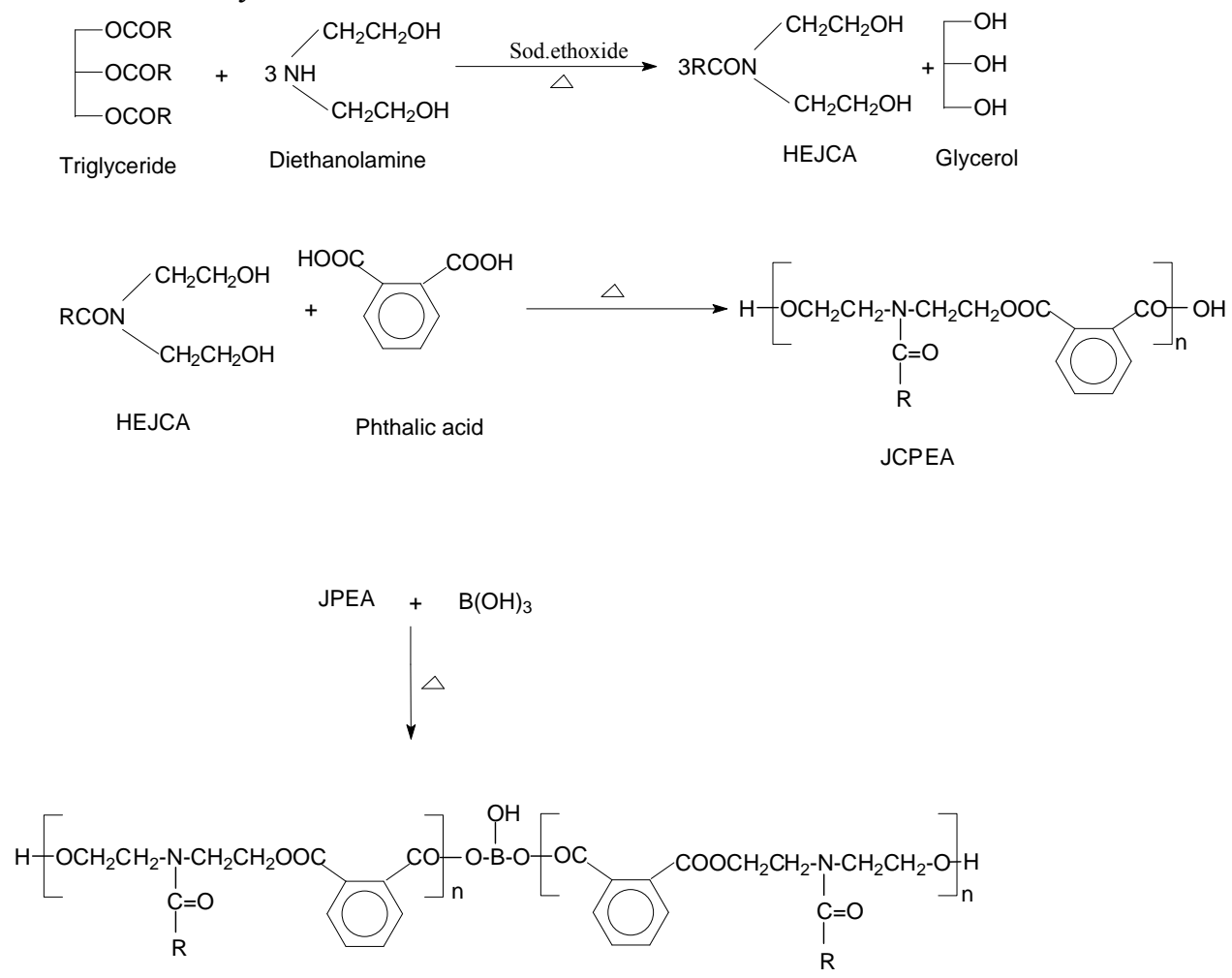

Figure 1. Synthesis of boron modified polyeste amide (JCBPEA)

The FT-IR spectrum of JCBPEA shows the broad and spread band at $3120-3650 \mathrm{~cm}^{-1}$ for the $\mathrm{OH}$ stretching vibration, broadening is attributed due to the remaining $-\mathrm{OH}$ of boric acid $^{20}$. The band for Ar-H appears at 3064 where as bands at $2972 \mathrm{~cm}^{-1}$ and $2882 \mathrm{~cm}^{-1}$ for $-\mathrm{CH}_{2}$ - asymmetric and symmetric stretching respectively. The bands for carbonyls of repeating ester and amide appear at $1770 \mathrm{~cm}^{-1}$ and $1684 \mathrm{~cm}^{-1}$ respectively. The band for the borate linkage appears at $1360 \mathrm{~cm}^{-1}$ and characteristic band for the disubstituted benzene ring appears at $776 \mathrm{~cm}^{-1}$. The ${ }^{1} \mathrm{H}$ NMR spectrum of JCBPEA show the sharp peak of chain $-\mathrm{CH}_{2}$ - adjacent to ester at $2.1 \mathrm{ppm}$, multiplet peak for the $-\mathrm{CH}=\mathrm{CH}-$ appears at $\delta=5.31-5.37$ ppm, aromatic proton appears at $\delta=7.8-8.6 \mathrm{ppm}$, broad peak for chain $-\mathrm{CH}_{2}$ - appears at $\delta=1.20-1.32 \mathrm{ppm}$ and terminal $-\mathrm{CH}_{3}$ appears at $\delta=0.93 \mathrm{ppm}$. It has been found that peak for the aromatic proton shifted towards down field due the presence of boron in polymer backbone ${ }^{20} .{ }^{13} \mathrm{C}$ NMR spectrum of JCBPEA shows the peaks at $\delta=174.4 \mathrm{ppm}$ and 163.8 ppm carbonyl of ester and amide respectively ${ }^{20}$. Closely spaced peaks at $\delta=128.8-132.6$ ppm due to carbons of aromatic ring where as double bounded carbons of fatty amide appears at $\delta=127.6-130.2 \mathrm{ppm}$. Peaks for chain $\mathrm{CH}_{2}$ of fatty amide appears at $\delta=24.4-30.8$ ppm while carbon of terminal methyl appears at $\delta=15.4 \mathrm{ppm}$. 


\section{Coating properties}

Coatings of JCPEA and JCBPEA were developed on standard size of mild steel strips for physico-mechanical and chemical corrosion/ resistance performances. It has been observed that optimum baking time and temperature both decreases significantly on incorporation of boron in the backbone of the polymeric chain. This can be attributed to the incorporation of boron increases the chain length of polymeric resin which required fever cross-link to form coherent film ${ }^{21}$. Coatings of both JCPEA and JCBPEA were pass the bending test on $1 / 8$ inch conical mandrel, no visual cracks were observed, characteristic of oil based polymeric coating materials. Coatings of JCBPEA show remarkably high values for scratch hardness and impact resistance, reasonably due to incorporation of boron increase the chain length of polymer, which provide cross-linked flexible coating material with good stiffness. The presence of pendent hydroxyl group on the boron in the polymer backbone also confers the adhesion between polymeric chain and metal surface ${ }^{21}$. The same can be attributed to higher gloss value and other physic-chemical performances. The presence of boron in the JCBPEA also enhances the protective ability of the film in different corrosive environments such as humid, acidic, alkaline and saline. These properties can also correlate to incorporation of boron in resin which improves the cross-link density. The hydroxyl group on boron provides extra cross-linking sites as well as improves the adhesion between metal surface and coating material.

\section{Conclusion}

Jatropha curcas seed oil a renewable and abundantly available raw material utilized successfully in the synthesis of boron incorporated polyesteramide resins. Incorporation of boron in the polyesteramide not only reduced the baking temperature and time for curing but also improves the physic-mechanical and corrosion/chemical resistance performances appreciably. These studies, therefore suggest that synthesis JCBPEA, provide a profitable and more practicable utility to Jatropha curcas seed oil.

\section{Acknowledgement}

The authors would like to thanks the authorities of G.F. College, Shajahanpur, UP, India for providing necessary facilities for carrying out this study.

\section{References}

1. Ahmad S, Ashraf S M, Hasnat A, Yadav S and Jamal A, J Appl Polym Sci., 2001, 82(8), 1855-1865; DOI:10.1002/app.2029

2. Ahmad S, Ashraf S M, Naqvi F, Yadav S and Hasnat A, Prog Org Coat., 2003, 47(2), 95-102; DOI:10.1016/S0300-9440(03)00015-8

3. Ahmad S, Ashraf S M, Kumar S, Alam M and Hasnat A, Indian J Chem Technol., 2005, 12, 193-197.

4. Ansrai S H, Naseem M, Hasnat A and Ahmad S A, Biosci Biotech Res Asia, 2011, 8(2), 829-832; DOI:10.13005/bbra/944

5. Ansari S H, Imran G, Naseem M, Ahmad S A and Hasnat A, Orient J Chem., 2012, 28, 607-612.

6. Akintayo C O and Akintayo E T, World Appl Sci J., 2010, 11, 1408-1415.

7. Ahamad S, Imran G, Ahmad S and Hasnat A, Chem Sci Trans., 2015, 4(3), 858-864; DOI: $10.7598 /$ cst2015.1060

8. Islam M R, Beg M D H and Jamari S S, J Appl Polym Sci., 2014, 131(18), 4078740799; DOI:10.1002/app.40787 
9. Zafar F, Ashraf S M and Ahmad S, Reactive Functional Polym., 2007, 67(10), 928935; DOI:10.1016/j.reactfunctpolym.2007.05.018

10. Samarth N B and Mahanwar P A, Open J Org Polym Mater., 2015, 5, 1-22.

11. Ahmad S, Ashraf S M, Sharmin E, Zafar F and Hasnat A, Prog Crystal Growth Charact Mater., 2002, 45(1-2), 83-88; DOI:10.1016/S0960-8974(02)00031-1

12. Ahmad S, Ashraf S M, Hasnat A and Noor A, Indian J Chem Technol., 2001, 8, 176180.

13. Pfister D P and Laroak R C, J Appl Polym Sci., 2012, 123(3), 1392-1400; DOI:10.1002/app.33636

14. Guner F S, Yagci Yand Erciyes A T, Prog Polym Sci., 2006, 31(7), 633-670; DOI:10.1016/j.progpolymsci.2006.07.001

15. Gao J, Lio Y and Wang F, Eur Polym J., 2001, 37(1), 207-210; DOI:10.1016/S00143057(00)00095-1

16. Abdalla M O, Ludwick A and Mitchell T, Polymer, 2003, 44(24), 7353-7359; DOI:10.1016/j.polymer.2003.09.019

17. Ambastha S P, Useful Plants of India, CSIR, New Delhi 1986.

18. Imran G, Ahamad S and Ahmad S A, Orient J Chem., 2015, 31, 553-556.

19. Ahmad S, Ashraf S M, Naqvi F, Yadav S and Hasnat A, J Polym Mater., 2001, 18, 53-60.

20. Silverstein R M, Bassler G C \& Morril T C, Spectroscopic identification of organic compounds, $5^{\text {th }}$ Edn., John Wile y \& Sons, New York, 1991.

21. Sounders K J, Organic Polymer Chemistry, $2^{\text {nd }}$ Edn., Chapman and Hall, USA, 1988. 